\title{
Efeito Residual de Sulfentrazone, Isoxaflutole e OXYFluorfen EM TRÊS SOLOS ${ }^{1}$
}

\author{
Residual Effect of Sulfentrazone, Isoxaflutole and Oxyfluorfen in Three Soils
}

\author{
MELO, C.A.D. ${ }^{2,8}$, MEDEIROS, W.N. ${ }^{3}$, TUFFI SANTOS, L.D. ${ }^{4}$, FERREIRA, F.A. ${ }^{5,8}$, FERREIRA, G.L. ${ }^{6}$, \\ PAES, F.A.S.V. ${ }^{6}$ e REIS, M.R. ${ }^{7}$
}

\begin{abstract}
RESUMO - As características físicas e químicas do solo, além das condições climáticas, influenciam o comportamento de herbicidas aplicados em pré-emergência das plantas daninhas. Dessa forma, objetivou-se avaliar o efeito residual de sulfentrazone, isoxaflutole e oxyfluorfen em três solos. O ensaio foi conduzido em ambiente protegido e o delineamento experimental foi em blocos casualizados, com quatro repetições. Os tratamentos, para cada solo, foram dispostos em esquema fatorial $3 \times 5$, sendo três herbicidas e cinco épocas de semeadura após aplicação dos produtos. Os herbicidas sulfentrazone, oxyfluorfen e

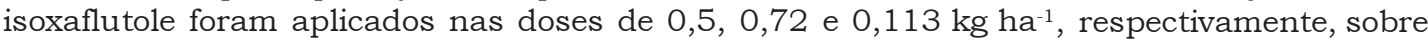
potes plásticos de $250 \mathrm{~mL}$ previamente preenchidos com os dois solos de textura argilosa e um de textura franco-arenosa. Posteriormente, procedeu-se à semeadura da espécie bioindicadora Sorghum bicolor de forma escalonada, aos 0, 15, 30, 45 e 60 dias após a aplicação (DAA). Uma testemunha sem herbicida foi semeada nas diferentes épocas para cada solo e usada como comparação nas avaliações. Aos 21 dias após a semeadura em cada época, realizaram-se avaliações de intoxicação e crescimento das plantas através da massa seca da parte aérea. As plantas de sorgo, no solo argiloso com 9,0 dag kg-1 de matéria orgânica (MO) submetido à aplicação de isoxaflutole, sulfentrazone e oxyfluorfen, produziram massa seca da parte aérea igual a 34, 20 e 40\%, respectivamente, aos 60 DAA, em relação às plantas crescidas nesse solo sem aplicação do herbicida. No solo franco-arenoso, observou-se elevado efeito residual dos herbicidas sulfentrazone e oxyfluorfen e diminuição do efeito residual do isoxaflutole ao longo do tempo, com 80, 90 e 40\% de controle aos 60 DAA, respectivamente. No solo argiloso com 4,4 dag kg-1 de $\mathrm{MO}$, verificou-se que o herbicida isoxaflutole perdeu a eficácia de controle ao longo do tempo, diferentemente do oxyfluorfen, que apresentou controle praticamente constante em todas as épocas avaliadas, e do sulfentrazone, que mostrou elevado efeito residual ao longo do período avaliado. As características inerentes a cada herbicida, bem como as diferenças nos teores de matéria orgânica e de textura entre os solos, influenciam na persistência do sulfentrazone, isoxaflutole e oxyfluorfen no solo. Maior efeito residual de oxyfluorfen foi observado no solo franco-arenoso e de isoxaflutole no solo argiloso com alto teor de matéria orgânica. Já o sulfentrazone apresentou elevado efeito residual nos três solos estudados.
\end{abstract}

Palavras-chave: herbicida, persistência, bioensaio, impacto ambiental.

ABSTRACT - The physical and chemical properties of soils, as well as climatic conditions, influence the behavior of herbicides applied in pre-emergence. This work aimed to evaluate the residual effect of sulfentrazone, isoxaflutole and oxyfluorfen in three soils. The trial was conducted in a protected environment in a randomized block experimental design, with four replications. The treatments for each soil were arranged in a $3 \times 5$ factorial, being three herbicides and five sowing periods after herbicide application. Sulfentrazone, isoxaflutole and oxyfluorfen were applied at $0.5 \mathrm{~kg} \mathrm{ha}^{-1}$,

Recebido para publicação em 5.11.2009 e na forma revisada em 12.11.2010.

2 Mestranda em Fitotecnia, Dep. de Fitotecnia, Universidade Federal de Viçosa - DFT/UFV, <chrisadinizmelo@yahoo.com.br>; ${ }^{3}$ Eng-o $-A g r{ }^{0}$. , UFV; ${ }^{4}$ Professor Adjunto I, Universidade Federal de Minas Gerais - UFMG; ${ }^{5}$ Professor Titular, DFT/UFV; ${ }^{6}$ Alunos de Graduação em Engenharia Florestal - DEF/UFV; ${ }^{7}$ Professor Adjunto, Universidade Federal de Viçosa, Campus Rio Paranaíba UFV-CRP, Rod. BR 354, km 310, Caixa Postal 22, 38810-000 Rio Paranaíba-MG; ${ }^{8}$ Bolsistas do CNPq. 


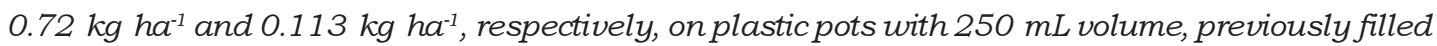
with the two clay texture soils and the sandy loam texture soil. Subsequently, the bioindicator species Sorghum bicolor was sown at 0, 15, 30, 45 and 60 days after application (DAA). A control with no herbicide treatment was sown at different times for each soil and used as a comparison in the evaluations. At 21 days after sowing in each season, intoxication and plant growth were evaluated by means of shoot dry mass. Sorghum plants in the clay soil with 9.0 dag kg-1 of organic matter (O.M.), submitted to the application of isoxaflutole, sulfentrazone and oxyfluorfen, produced shoot dry mass over the control to 34, 20 and 40\%, respectively, at 60 DAA. In the sandy loam soil, it was observed a high residual effect of sulfentrazone and oxyfluorfen, and a decrease in the residual effect of isoxaflutole overtime, with 80, 90 and $40 \%$ control at $60 \mathrm{DAA}$, respectively. In the clay soil with $4.4 \mathrm{dag} \mathrm{kg} \mathrm{kg}^{-1}$ of O.M., the herbicide isoxaflutole was found to lose control efficacy over time, unlike oxyfluorfen, which showed practically constant control in all the evaluated periods, and sulfentrazone, which showed high residual effect during the study period. The inherent characteristics of each herbicide, as well as the differences in organic matter content and texture between the soils influence the persistence of sulfentrazone, isoxaflutole and oxyfluorfen in the soil. Greater residual effect of oxyfluorfen was observed in sandy loam soil, and isoxaflutole in clay soil with high content of organic matter, while sulfentrazone presented high residual effect in the three soils.

Keywords: herbicide, persistence, bioassay, environmental impact.

\section{INTRODUÇÃO}

O uso correto de pesticidas, aliado aos avanços tecnológicos empregados nos cultivos, tem proporcionado aumento na produção e redução nas perdas ocasionadas por pragas, doenças e plantas daninhas. Todavia, a utilização desses compostos de modo indiscriminado representa alto risco de contaminação ambiental (Vivian et al. 2006).

Herbicidas aplicados em pré-emergência das plantas daninhas dependem de características do próprio produto, do solo e climáticas para sua ação e permanência no ambiente. Ao alcançarem o solo, dá-se início ao processo de redistribuição e degradação desses compostos, o qual pode ser extremamente curto, como o que ocorre com algumas moléculas simples e não persistentes, ou perdurar por meses ou anos, como ocorre com compostos altamente persistentes (Filizola et al., 2002).

O potencial de contaminação do lençol freático por herbicidas ou a sua permanência nas camadas superficiais do solo dependem, principalmente, de sua mobilidade no perfil do solo, a qual está direta e inversamente vinculada à sua capacidade de adsorção e degradação (Carter, 2000). Para Andréa \& Luchini (2002), a sorção de pesticidas no solo também é importante, principalmente por se relacionar diretamente com os processos de disponibilidade para a atividade do composto no controle de plantas daninhas, ataque microbiano e biodegradação e inversamente com a possibilidade de lixiviação e contaminação de águas.

A degradação microbiológica dos herbicidas é um importante mecanismo de decomposição e, dessa forma, de redução da persistência dos herbicidas no solo. Normalmente, incrementos na dissipação são esperados com o aumento do teor de matéria orgânica, aeração, umidade e temperatura do solo, visto que esses fatores regulam a atividade, a biomassa e a diversidade microbiana no solo e, em função disso, as possiveis transformações biológicas dos herbicidas no solo (Walker et al., 1992).

Em estudos sobre atividade de moléculas herbicidas nos solos, pesquisadores têm utilizado o bioensaio, que alia baixo custo a uma boa precisão. Essa técnica consiste em utilizar plantas sensiveis aos produtos testados, de forma que resíduos de herbicidas ou soluções presentes no solo possam ser evidenciados por meio da alteração das características agronômicas da planta-teste.

Na eucaliptocultura, o controle de plantas daninhas é feito basicamente pelo uso de herbicidas, sendo uma das alternativas a aplicação em pré-emergência de produtos como oxyfluorfen, isoxaflutole e sulfentrazone. O 
eucalipto é cultivado nas diferentes regiões do Brasil e numa grande variedade de solos. Dessa forma, é esperado que herbicidas aplicados em pré-emergência tenham comportamento diferenciado quanto a sua ação, a qual é altamente dependente de características como material de origem, granulometria, teores de matéria orgânica e umidade do solo.

Assim, é razoável admitir que a compreensão da atividade residual de sulfentrazone, isoxaflutole e oxyfluorfen sob diferentes condições químicas e texturais de solo pode, eventualmente, levar à adoção de estratégias corretas para o manejo da cultura, bem como à aplicação de doses menores desses produtos, o que, por sua vez, implica redução do aporte de pesticidas no solo e no ambiente.

Diante do exposto, considerando a importância do assunto e a carência de informações sobre o comportamento desses herbicidas sob condições tropicais, objetivou-se avaliar o efeito residual dos herbicidas sulfentrazone, isoxaflutole e oxyfluorfen em três solos com diferentes características químicas e texturais.

\section{MATERIAL E MÉTODOS}

O ensaio foi conduzido em ambiente protegido entre os meses de abril e julho de 2008, e constituiu-se de três experimentos, um para cada solo, nos quais foram testados os mesmos tratamentos e avaliadas as mesmas variáveis. O delineamento experimental utilizado para cada ensaio foi em blocos casualizados, com quatro repetições. Os tratamentos foram dispostos em esquema fatorial $3 \times 5$, sendo três herbicidas (sulfentrazone, isoxaflutole e oxyfluorfen) e cinco épocas de semeadura $(0,15,30,45$ e 60 dias após a aplicação - DAA).

Os solos utilizados possuem características químicas e físicas distintas e foram provenientes dos municípios de Viçosa, Virginópolis e Oratórios, no Estado de Minas Gerais, sendo dois solos argilosos com teores diferentes de matéria orgânica $\left(9,0\right.$ e 4,4 dag $\left.\mathrm{kg}^{-1}\right)$ e um solo franco-arenoso, respectivamente (Tabela 1).

Potes plásticos de $250 \mathrm{~mL}$ foram preenchidos com os solos previamente à aplicação dos herbicidas, para a qual utilizou-se um pulverizador costal com pressão constante mantida por $\mathrm{CO}_{2}$, acoplado de barra com um bico tipo leque TT11002, com pressão de trabalho de $250 \mathrm{Kpa}$ e volume de calda de $150 \mathrm{~L} \mathrm{ha}^{-1}$, aplicando-se as doses de $0,5 \mathrm{~kg} \mathrm{ha}^{-1}$ de sulfentrazone, $0,113 \mathrm{~kg} \mathrm{ha}^{-1}$ de isoxaflutole e $0,72 \mathrm{~kg} \mathrm{ha}^{-1}$ de oxyfluorfen, as quais correspondem à dose recomendada pelo fabricante para a cultura do eucalipto.

Posteriormente, procedeu-se à semeadura da espécie bioindicadora Sorghum bicolor de forma escalonada aos 0, 15, 30, 45 e 60 DAA, distribuindo-se cinco sementes por pote. Todos os potes foram mantidos sobre uma bancada e irrigados diariamente. Para cada solo foram mantidos quatro potes sem aplicação do herbicida, os quais foram considerados como

Tabela 1 - Resultados das análises química e física das amostras dos solos provenientes dos municípios de Viçosa, Virginópolis e Oratórios, Minas Gerais

\begin{tabular}{|c|c|c|c|c|c|c|c|c|c|}
\hline \multicolumn{10}{|c|}{ Caracterização química } \\
\hline \multirow{2}{*}{ Origem do solo } & \multirow{2}{*}{$\mathrm{pH}$} & $\mathrm{P}$ & $\mathrm{K}$ & $\mathrm{Al}$ & $\mathrm{H}+\mathrm{Al}$ & $\mathrm{Ca}$ & $\mathrm{Mg}$ & \multirow{2}{*}{$\frac{\text { M.O. }}{\left(\text { dag kg }^{-1}\right)}$} & \multirow{2}{*}{$\frac{\text { P-rem }}{\left(\mathrm{mg} \mathrm{L}^{-1}\right)}$} \\
\hline & & \multicolumn{2}{|c|}{$\left(\mathrm{mg} \mathrm{dm}^{-3}\right)$} & \multicolumn{4}{|c|}{$\left(\mathrm{cmol}_{\mathrm{c}} \mathrm{dm}^{-3}\right)$} & & \\
\hline Viçosa & 5,52 & 182,0 & 1.000 & 0,00 & 8,7 & 4,71 & 2,92 & 9,00 & 45,3 \\
\hline Virginópolis & 4,73 & 8,1 & 18 & 0,67 & 11,4 & 0,48 & 0,05 & 4,43 & 16,5 \\
\hline Oratórios & 5,84 & 12,4 & 110 & 0,00 & 4,1 & 1,21 & 0,58 & 0,40 & 37,7 \\
\hline \multicolumn{10}{|c|}{ Caracterização física } \\
\hline \multirow{2}{*}{ Origem do solo } & Argila & & & Areia fina & Areia grossa & & \multirow{2}{*}{\multicolumn{3}{|c|}{ Classe textural }} \\
\hline & \multicolumn{5}{|c|}{$\left(\right.$ dag kg $\left.{ }^{-1}\right)$} & & & & \\
\hline Viçosa & \multicolumn{2}{|l|}{56} & 8 & 16 & 20 & & \multicolumn{2}{|c|}{ Argila } & \\
\hline Virginópolis & \multicolumn{2}{|l|}{54} & & 9 & 31 & & \multicolumn{2}{|c|}{ Argila } & \\
\hline Oratórios & 14 & \multicolumn{2}{|c|}{14} & 47 & 25 & & \multicolumn{2}{|c|}{ Franco-arenosa } & \\
\hline
\end{tabular}


testemunha, para cada época de semeadura. Os dados referentes à temperatura e umidade relativa do ar durante o período experimental encontram-se na Figura 1.

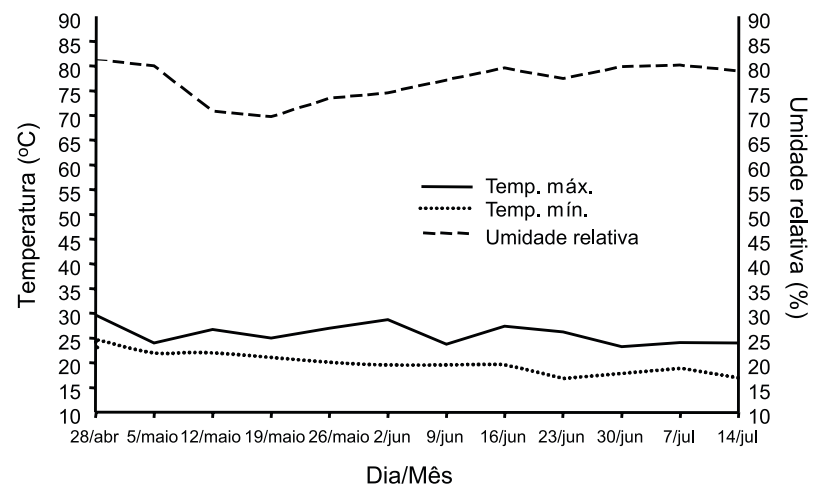

Figura 1 - Médias semanais de umidade relativa (\%) e temperaturas máxima e mínima do ar $\left({ }^{\circ} \mathrm{C}\right)$ observadas durante a condução do ensaio.

Foram realizadas avaliações de intoxicação e crescimento das plantas através da massa seca da parte aérea aos 21 dias após a semeadura em cada época. Para avaliação de intoxicação utilizou-se uma escala de intoxicação, na qual as notas são referentes à porcentagem de área foliar afetada por injúrias ocasionadas pelo contato com o herbicida em relação à área foliar total da planta, em que $0 \%$ representa ausência de injúrias e $100 \%$ a morte da planta.

$\mathrm{Na}$ interpretação dos resultados, após a análise de variância a 5\% de significância pelo teste $\mathrm{F}$, utilizou-se a análise de regressão para os fatores quantitativos.

\section{RESULTADOS E DISCUSSÃO}

\section{Solo de textura argilosa com $9,0 \mathrm{dag} \mathrm{kg}^{-1}$ de MO}

Observou-se resposta linear positiva na produção de massa seca da parte aérea das plantas de sorgo à medida que se distanciava do dia da aplicação de isoxaflutole (Figura 2). Contudo, até os 60 DAA esse herbicida apresentou efeito residual alto, evidenciado pela baixa produção de massa seca (34\%) em relação à testemunha (Figura 2) e pelas elevadas notas de intoxicação das plantas (Tabela 2).
Monquero et al. (2008) estudaram a persistência do isoxaflutole em amostras de Latossolo Vermelho distrófico (textura média) e Latossolo Vermelho distroférrico (textura argilosa) e evidenciaram também efeito residual satisfatório (>70\%) até $60 \mathrm{DAA}$, não havendo diferenças estatísticas entre os tipos de solo. Em trabalhos anteriores, constatouse que o isoxaflutole apresentou alta estabilidade no solo de textura argilosa mesmo após três chuvas simuladas de $20 \mathrm{~mm}$, espaçadas de 30 dias e seguidas de 120 dias de seca após sua aplicação (Oliveira Júnior et al., 2006).

Marchiori Jr. et al. (2005) verificaram maior estabilidade e persistência do efeito residual do isoxaflutole em solo argiloso (Latossolo Vermelho distroférrico), quando comparado com solo franco-arenoso (Latossolo Vermelho distrófico), independentemente da dose, do bioindicador e do periodo de seca após a aplicação do herbicida, atribuindo esse fato às diferenças nos teores de carbono orgânico e argila entre os dois solos $\left(10,30 \times 3,07 \mathrm{mg} \mathrm{dm}^{-3}\right.$ e $72 \times 27 \%$, respectivamente para o Latossolo Vermelho distroférrico e distrófico). Esses resultados devem-se provavelmente ao fato de que as argilas, juntamente com a matéria orgânica, apresentam grande superficie específica e elevada capacidade de retenção e trocas iônicas - propriedades que proporcionam menor exposição do produto aos processos de degradação e transporte, o que prolongou o efeito residual do isoxaflutole (IFT) no solo de textura argilosa.

O herbicida sulfentrazone aplicado diretamente no solo foi eficiente no controle do bioindicador até 60 DAA, com produção de massa seca inferior a 20\% (Figura 2) e elevado efeito fitotóxico (Tabela 2) ao longo desse período.

Reddy \& Locke (1998) observaram que, independentemente do tipo de manejo, a taxa de sorção de sulfentrazone foi maior no solo argiloso e a dessorção se deu de forma bem lenta. Segundo esses autores, a alta sorção e baixa dessorção garantem ao sulfentrazone longa permanência no solo, a qual é favorecida também pela sua baixa mineralização.

Nas avaliações de persistência do herbicida oxyfluorfen, observou-se incremento na produção de massa seca da parte aérea das 

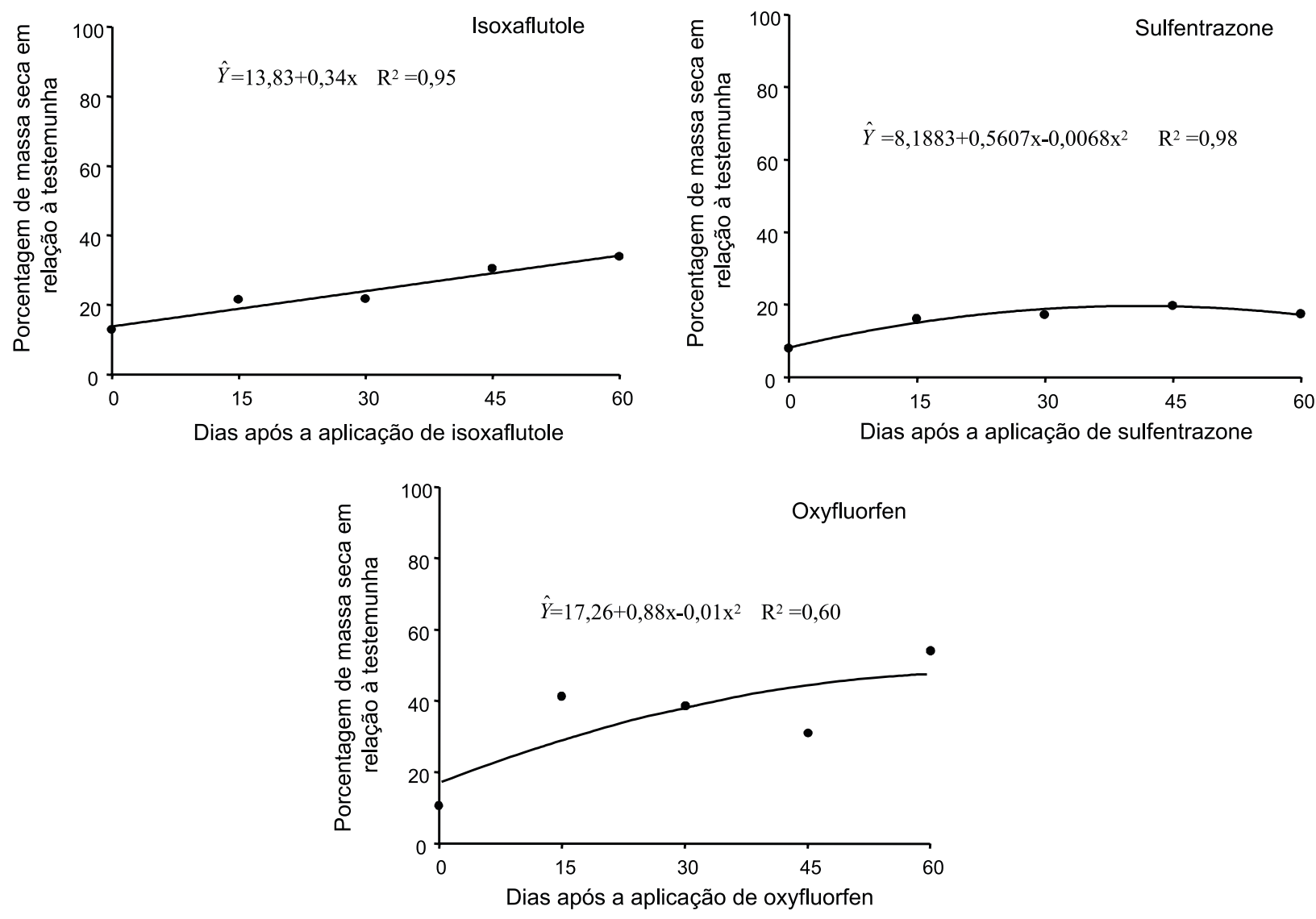

Figura 2 - Porcentagem de massa seca em relação à testemunha da parte aérea de plantas de sorgo, cultivadas em solo de textura argilosa com 9,0 dag kg-1 de MO, após aplicação dos herbicidas isoxaflutole, sulfentrazone e oxyfluorfen e semeadura escalonada.

plantas de sorgo com o passar do tempo, apresentando, aos 60 DAA, cerca de $50 \%$ de controle (Figura 2). As notas de intoxicação evidenciam diminuição na concentração do herbicida oxyfluorfen no solo ao longo dos períodos avaliados (Tabela 2).

\section{Solo de textura franco-arenosa}

Observou-se neste solo elevado efeito residual dos herbicidas sulfentrazone e oxyfluorfen e diminuição do efeito residual do isoxaflutole ao longo do tempo, com 80,90 e $40 \%$ de controle aos 60 DAA, respectivamente (Figura 3).

Ao avaliar o herbicida isoxaflutole, observou-se, através da porcentagem de massa seca em relação à testemunha (Figura 3) e das notas de intoxicação decrescentes (Tabela 3), que houve diminuição na concentração do herbicida livre no solo, o que provavelmente se deve às características desse solo, como, por exemplo, menor quantidade de sitios sortivos disponiveis, os quais conferem menor sorção de IFT e, consequentemente, perda do efeito residual com o tempo.

Tabela 2 - Intoxicação de plantas de sorgo cultivadas em solo de textura argilosa com 9,0 dag $\mathrm{kg}^{-1}$ de $\mathrm{MO}$, após aplicação dos herbicidas sulfentrazone, isoxaflutole e oxyfluorfen e semeadura escalonada

\begin{tabular}{|c|c|c|c|}
\hline \multirow{2}{*}{$\begin{array}{c}\text { Época de } \\
\text { semeadura }\end{array}$} & \multicolumn{3}{|c|}{ Herbicida } \\
\cline { 2 - 4 } & sulfentrazone & isoxaflutole & oxyfluorfen \\
\hline 0 DAA & 100,0 & 96,0 & 96,0 \\
\hline 15 DAA & 80,0 & 76,0 & 55,0 \\
\hline 30 DAA & 98,4 & 81,0 & 53,0 \\
\hline 45 DAA & 98,4 & 76,0 & 85,0 \\
\hline 60 DAA & 98,0 & 79,0 & 78,0 \\
\hline
\end{tabular}



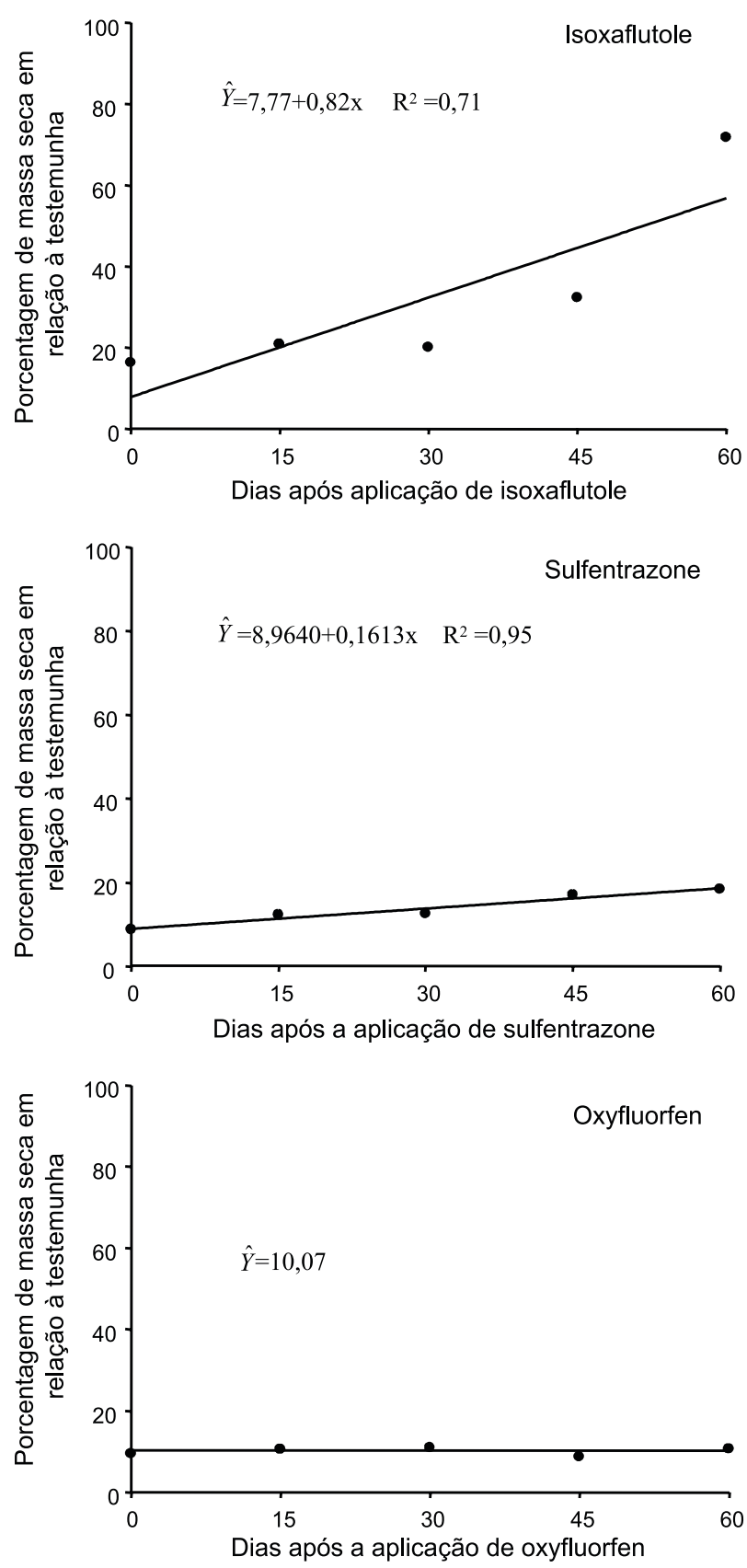

Figura 3 - Porcentagem de massa seca em relação à testemunha da parte aérea de plantas de sorgo, cultivadas em solo de textura franco-arenosa, após aplicação dos herbicidas isoxaflutole, sulfentrazone e oxyfluorfen e semeadura escalonada.

Quanto ao herbicida sulfentrazone, sua atividade residual diminuiu ao longo do tempo, com pequeno incremento na produção de massa seca da parte aérea das plantas de sorgo em relação à testemunha (Figura 3), porém apresentou efeito residual satisfatório, com elevada intoxicação das plantas até os 60 DAA (Tabela 3).

Não foi observada diferença significativa na porcentagem de massa seca da parte aérea das plantas entre as épocas de semeadura após a aplicação de oxyfluorfen, o qual apresentou controle máximo do bioindicador (Tabela 3), indicando elevada persistência deste no solo (Figura 3).

A atividade residual dos herbicidas pode sofrer influências não só de características físicas e químicas do solo, como também das condições climáticas, principalmente temperatura, umidade e exposição à radiação solar. Segundo Rodrigues \& Almeida (2005), o efeito residual do oxyfluorfen é mais prolongado em ambiente com umidade elevada e protegido da incidência de raios solares, visto que uma das rotas de sua degradação é a fotólise. Assim, sua ação foi prolongada em razão de os potes permanecerem em ambiente protegido e com umidade em torno de $80 \%$ da capacidade de campo, mantida por meio de irrigações diárias. Também, Cassamassimo (2005), avaliando a dissipação de oxyfluorfen em solos com atividades florestais, sombreados e a pleno sol, constatou dissipação mais lenta do herbicida nas áreas sombreadas, enquanto Yen et al. (2003) verificaram que temperaturas elevadas aumentam a taxa de dissipação do oxyfluorfen.

\section{Solo de textura argilosa com $4,4 \mathrm{dag}^{\mathrm{kg}}{ }^{-1}$ de MO}

A eficácia de controle do isoxaflutole diminuiu ao longo do tempo, apresentando aos 60 DAA porcentagem de massa seca das plantas de sorgo, em relação à testemunha, superior a $80 \%$ (Figura 4), fato que evidencia que, à medida que aumenta o tempo entre a aplicação do herbicida e a semeadura do bioindicador, há redução no potencial efetivo de controle, possivelmente pela diminuição da sua disponibilidade na solução do solo. A mesma tendência foi observada na Tabela 4, com apenas $7 \%$ de injúrias nas plantas nessa mesma época avaliada.

No solo, o IFT é rapidamente convertido em metabólito diquetonitrila (DKN), que é a molécula biologicamente ativa no controle de plantas daninhas. O DKN é mais solúvel (326 $\left.\mathrm{mg} \mathrm{L}^{-1}\right)$, 
Tabela 3 - Intoxicação, em \%, de plantas de sorgo cultivadas em solo de textura franco-arenosa, após aplicação dos herbicidas sulfentrazone, isoxaflutole e oxyfluorfen e semeadura escalonada

\begin{tabular}{|c|c|c|c|}
\hline \multirow{2}{*}{$\begin{array}{c}\text { Época de } \\
\text { semeadura }\end{array}$} & \multicolumn{3}{|c|}{ Herbicida } \\
\cline { 2 - 4 } & sulfentrazone & isoxaflutole & oxyfluorfen \\
\hline 0 DAA & 100,0 & 100,0 & 100,0 \\
\hline 15 DAA & 99,4 & 97,0 & 100,0 \\
\hline 30 DAA & 99,6 & 97,4 & 100,0 \\
\hline 45 DAA & 99,2 & 82,0 & 99,8 \\
\hline 60 DAA & 99,4 & 8,0 & 100,0 \\
\hline
\end{tabular}
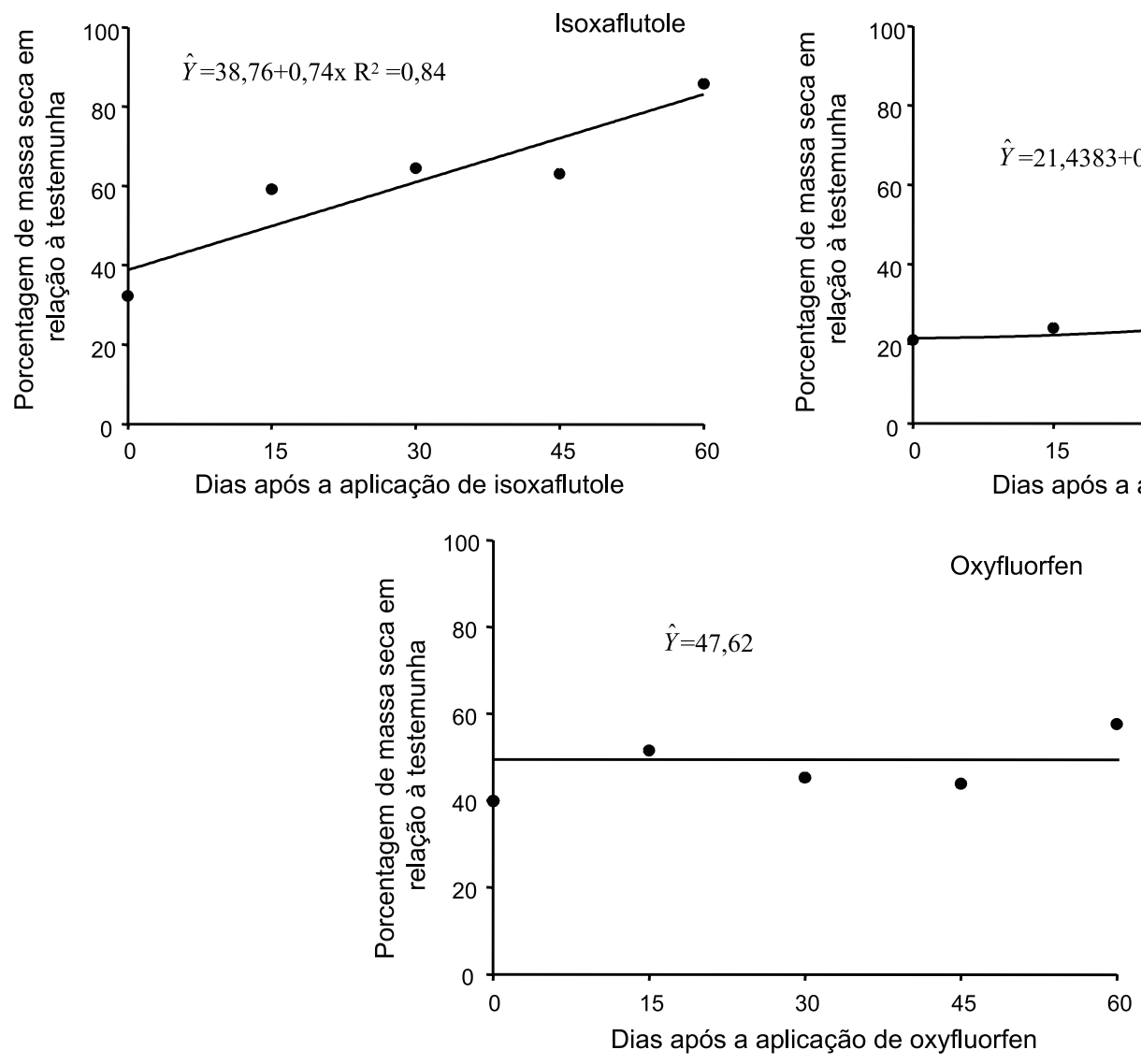

Figura 4 - Porcentagem de massa seca em relação à testemunha da parte aérea de plantas de sorgo, cultivadas em solo de textura argilosa com 4,4 dag $\mathrm{kg}^{-1}$ de $\mathrm{MO}$, após aplicação dos herbicidas isoxaflutole, sulfentrazone e oxyfluorfen e semeadura escalonada.

mais estável e mais persistente que o IFT (Taylor-Lovell et al., 2000, 2002; Mitra et al., 2000). Posteriormente, o DKN é convertido em ácido benzoico, que é considerado um metabólito biologicamente inativo, embora muito estável. Uma vez que a solubilidade do DKN em
Tabela 4 - Intoxicação de plantas de sorgo cultivadas em solo de textura argilosa com 4,4 dag $\mathrm{kg}^{-1}$, após aplicação dos herbicidas sulfentrazone, isoxaflutole e oxyfluorfen e semeadura escalonada

\begin{tabular}{|c|c|c|c|}
\hline \multirow{2}{*}{$\begin{array}{c}\text { Época de } \\
\text { semeadura }\end{array}$} & \multicolumn{3}{|c|}{ Herbicida } \\
\cline { 2 - 4 } & ulfentrazone & isoxaflutole & oxyfluorfen \\
\hline 0 DAA & 100,0 & 95,0 & 95,4 \\
\hline 15 DAA & 76,0 & 23,0 & 63,0 \\
\hline 30 DAA & 92,8 & 44,0 & 70,0 \\
\hline 45 DAA & 91,4 & 46,0 & 74,0 \\
\hline 60 DAA & 94,0 & 7,0 & 72,0 \\
\hline
\end{tabular}

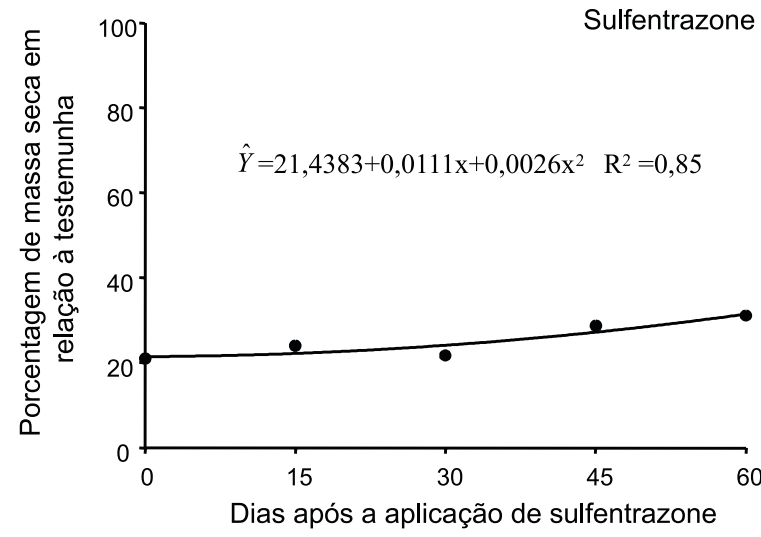

Oxyfluorfen água é cerca de 50 vezes maior do que a do IFT, espera-se maior disponibilidade de DKN na solução do solo com menor sorção (TaylorLovell et al., 2000), a qual também diminui com o decréscimo de matéria orgânica presente no solo (Mitra et al., 2000). 
Na Figura 4, observa-se elevado efeito residual de sulfentrazone até os 60 DAA. A persistência de sulfentrazone em um Latossolo Vermelho-Amarelo, segundo Vivian et al. (2006), é elevada e, dependendo da dose, causa efeito negativo sobre microrganismos do solo.

Blanco et al. (2005) definiram como 376 DAA o limite final da persistência do herbicida sulfentrazone, na dose de $0,6 \mathrm{~kg} \mathrm{ha}^{-1}$ e aplicado em solo argiloso, limite este obtido quando os testes estatísticos revelaram que somente a partir dessa época não houve diferença em relação à testemunha sem aplicação desse produto.

Quanto ao efeito residual de oxyfluorfen neste solo, não houve diferença significativa entre as porcentagens de massa seca das plantas de sorgo semeadas ao longo dos 60 DAA (Figura 4) e diferentemente do resultado encontrado no solo argiloso com maior teor de matéria orgânica, neste houve menor efeito residual e ação herbicida (Tabela 4), possivelmente pela menor concentração de resíduo disponível na solução do solo.

As características inerentes a cada herbicida, bem como as diferenças nos teores de matéria orgânica e de textura entre os solos, influenciam na persistência do sulfentrazone, isoxaflutole e oxyfluorfen no solo.

Elevado efeito residual de oxyfluorfen e sulfentrazone foi observado no solo francoarenoso, bem como de isoxaflutole no solo argiloso com alto teor de MO. Dos herbicidas estudados, o sulfentrazone foi o que apresentou maior efeito residual ao longo dos 60 dias nos três solos.

\section{AGRADECIMENTOS}

À Celulose Nipo Brasileira - CENIBRA e ao Conselho Nacional de Desenvolvimento Científico e Tecnológico - CNPq, pelo suporte financeiro.

\section{LITERATURA CITADA}

ANDREA; M. M.; LUCHINI, L. C. Comportamento de pesticidas em solos brasileiros: a experiência do Instituto Biológico/SP. B. Inf. SBCS, v. 27, n. 2, p. 22-24, 2002

BLANCO, F. M. G.; VELINI, E. D. Persistência do herbicida sulfentrazone em solo cultivado com soja e seu efeito em culturas sucedâneas. Planta Daninha, v. 23, n. 4, p. 693-700, 2005.

CARTER, A. D. Herbicide movement in soils: principles, pathways and processes. Weed Res., v. 40, p. 113-122, 2000

CASSAMASSIMO, R. E. Dissipação e mobilidade dos herbicidas gliphosato e oxyfluorfen em solos com atividades florestais. 2005. 62 f. Dissertação (Mestrado em Recursos Florestais) - Escola Superior de Agricultura Luiz de Queiroz, Piracicaba, 2005.

FILIZOLA, H. F. et al. Monitoramento e avaliação do risco de contaminação por pesticidas em água superficial e subterrânea na região de Guairá. Pesq. Agropec. Bras., v. 37 , n. 5, p. 659-667, 2002.

MARCHIORI JR., O. et al. Efeito residual de isoxaflutole após diferentes períodos de seca. Planta Daninha, v. 23, n. 3, p.491-499, 2005

MITRA, S.; BHOWMILK, P. C.; XING, B. Sorption and desorption of the diketonitrile metabolite of isoxaflutole in soils. Environ. Poll., v. 108, n. 1, p. 183-190, 2000.

MONQUERO, P. A. et al. Mobilidade e persistência de herbicidas aplicados em pré-emergência em diferentes solos. Planta Daninha, v. 26, n. 1, p. 411-417, 2008.

OLIVEIRA JÚNIOR, R. S. et al. Influência do período de restrição hídrica após a aplicação na atividade residual no solo do isoxaflutole. Planta Daninha, v. 24, n. 4, p. 733-740, 2006.

REDDY, K. N.; LOCKE, M. A. Sulfentrazone sorption, desorption, and mineralization in soils from two tillage systems. Weed Sci., v. 46, n. 4, p. 494-500, 1998.

RODRIGUES, B. N.; ALMEIDA, F. S. Guia de herbicidas. 3.ed. Londrina: IAPAR, 2005. 591 p.

TAYLOR-LOVELL, S. et al. Hydrolysis and soil adsorption of the labile herbicide isoxaflutole. Environ. Sci. Technol., v. 34, p. 3186-3190, 2000. 